\title{
Stratospheric ozone variations in the equatorial region as seen in Stratospheric Aerosol and Gas Experiment data
}

\author{
$\operatorname{AUTHOR}(\mathrm{S})$ :
}

Shiotani, Masato; Hasebe, Fumio

\section{CITATION:}

Shiotani, Masato ... [et al]. Stratospheric ozone variations in the equato rial region as seen in Stratospheric Aerosol and Gas Experiment data. Journal of Geophysical Research: Atmospheres 1994, 99(D7): 14575-14584

\section{ISSUE DATE:}

1994-07-20

URL:

http://hdl.handle.net/2433/217092

\section{RIGHT:}

C 1994 American Geophysical Union. Further reproduction or electronic distribution is not permitted. 


\title{
Stratospheric ozone variations in the equatorial region as seen in Stratospheric Aerosol and Gas Experiment data
}

\author{
Masato Shiotani ${ }^{1}$ \\ National Center for Atmospheric Research, Boulder, Colorado \\ Fumio Hasebe ${ }^{2}$ \\ Institute for Terrestrial and Planetary Atmospheres, State University of New York, Stony Brook
}

\begin{abstract}
An analysis is made of equatorial ozone variations for 5 years, 1984-1989, using the ozone profile data derived from the Stratospheric Aerosol and Gas

Experiment II (SAGE II) instrument. Attention is focused on the annual cycle and also on interannual variability, particularly the quasi-biennial oscillation (QBO) and El Niño-Southern Oscillation (ENSO) variations in the lower stratosphere, where the largest contribution to total column ozone takes place. The annual variation in zonal mean total ozone around the equator is composed of symmetric and asymmetric modes with respect to the equator, with maximum contributions being around $19 \mathrm{~km}$ for the symmetric mode and around $25 \mathrm{~km}$ for the asymmetric mode. The persistent zonal wavenumber 1 structure observed by the total ozone mapping spectrometer over the equator is almost missing in the SAGE-derived column amounts integrated in the stratosphere, suggesting a significant contribution from tropospheric ozone. Interannual variations in the equatorial ozone are dominated by the QBO above $20 \mathrm{~km}$ and the ENSO-related variation below $20 \mathrm{~km}$. The ozone QBO is characterized by zonally uniform phase changes in association with the zonal wind QBO in the equatorial lower stratosphere. The ENSO-related ozone variation consists of both the east-west vacillation and the zonally uniform phase variation. During the El Niño event, the eastwest contrast with positive (negative) deviations in the eastern (western) hemisphere is conspicuous, while the decreasing tendency of the zonal mean values is maximum at the same time.
\end{abstract}

\section{Introduction}

The understanding of the exchange processes between the troposphere and the stratosphere for various atmospheric constituents is important in describing the ozone distribution and temperature structure that are mutually dependent on each other. Particularly in the equatorial regions, convective cloud activity varies over a wide range of space and time scales and is accompanied by an upward flow, resulting in the intrusion of tropospheric air into the stratosphere. One of the most dramatic changes in convective cloud activity is associated with the El Niño-Southern Oscillation (ENSO) cycle, which has a timescale of about 4 years. Though the ENSO was originally regarded as an ocean-atmosphere coupled variation confined mostly to the tropical Pacific Ocean, observational evidence suggests possible influences on extratropical circulation and stratospheric circulation [e.g., Randel and Cobb, 1993]. Despite the great significance of the tropical region in the global atmospheric circulation system, observations at equatorial latitudes have been quite

\footnotetext{
${ }^{1}$ Now at Department of Geophysics, Faculty of Science, Kyoto University, Kyoto, Japan.

${ }^{2}$ Now at Department of Earth Sciences, Faculty of Science, Ibaraki University, Mito, Japan.

Copyright 1994 by the American Geophysical Union.

Paper number 94JD00741.

0148-0227/94/94JD-00741\$05.00
}

limited, and consequently, our understanding of the equatorial atmosphere is still incomplete.

Motivated by these important issues associated with the equatorial atmosphere, Shiotani [1992] (hereinafter referred to as $\mathbf{S 9 2 )}$ made an analysis of total ozone variations by using the 11-year global data derived from the total ozone mapping spectrometer (TOMS) instrument on board the Nimbus 7 satellite. In the equatorial total ozone field, $S 92$ found three dominant frequency components.

Annual cycle. Zonal mean values for total ozone are maximum around September and minimum around January. Zonal wave components are characterized by the wave 1 structure, which is persistent throughout the year, with minimum values in the western Pacific.

Quasi-biennial oscillation (QBO) cycle. Total ozone anomalies (deviations from climatological annual cycle) are dominated by the QBO component, which is distinguished for the zonally uniform phase changes in conjunction with the equatorial zonal wind $\mathrm{QBO}$.

ENSO cycle. The longitudinal seesaw variation of total ozone, having a characteristic time scale of about 4 years, is apparently related to the ENSO cycle. The nodal longitude is located around the date line, reflecting the eastward migration of the active convective region associated with the El Nin̄o event.

Dynamical responses of the equatorial total ozone to sea surface temperature (SST) changes have been investigated by Hasebe [1993] (hereinafter referred to as H93). He 
performed simple mechanistic calculations keeping in mind the following two dynamical effects.

The tropopause effect. This accounts for the total ozone variations accompanied by altitude changes of the tropopause. A higher tropopause results in a deeper layer with a characteristically low tropospheric ozone concentration and therefore a smaller amount of total ozone.

The advection effect. This effect involves those variations associated with the vertical ozone advection caused by diabatically driven mean meridional circulation. Enhanced upward motion in the lower stratosphere will reduce the total ozone amount by the extent of countergradient vertical ozone advection.

The total ozone variations estimated by $\mathrm{H} 93$ from the ENSO timescale SST changes agree reasonably well with observations supporting the hypothesis presented by $\mathbf{\$ 9 2}$. The scenario predicts that a higher tropopause and a stronger upward motion result when higher SSTs activate more vigorous convective cloud activities. Because the advection effect expresses a decreasing tendency while the tropopause effect describes an instantaneous low value of total ozone at the time of high SSTs, the two effects appear with a phase difference of a quarter cycle on ozone variations (see $\mathrm{H} 93$ for details).

In this paper, long-term variations in vertical profiles of the equatorial ozone field are investigated by using the Stratospheric Aerosol and Gas Experiment II (SAGE II) ozone profile data for 5 years from 1984 to 1989 . The goal of this study is to provide direct observational support for the hypotheses about and model results for the mechanism of ozone variations put forth by $\mathrm{S} 92$ and $\mathrm{H} 93$. The use of the SAGE data makes it possible to identify the height range in which each of the total ozone variations is dominant. As an extension of S92, we will also pay special attention to the longitudinal structure of the ozone field.

\section{Data}

For the following study, we make use of the SAGE ozone data published on CD-ROM by NASA's Climate Data System for the project Greenhouse Effect Detection Experiment (GEDEX). Details of SAGE observations are described by McCormick et al. [1979, 1989]. The SAGE uses the solar occultation technique for providing vertical profiles of stratospheric ozone, nitrogen dioxide, water vapor, and aerosols at satellite sunrise and sunset. In the present analysis, we focus only on ozone data, although an understanding of variations between these constituents and a synthesis of them will be required eventually. The advantages of the solar occultation technique are high accuracy and high vertical resolution in observed ozone profiles. The disadvantage of the SAGE observation is that it cannot provide a global map on a daily basis; instead, its spatial coverage is limited to almost one latitude circle per day. However, the SAGE can provide a global map approximately once per month, since the SAGE observation passes between the southernmost latitude and the northernmost latitude about 10 times a year [e.g., McCormick et al., 1989, Figure 1]. Therefore the SAGE data are applicable to an investigation into long-term variations with the capability of describing a longitudinal structure.

Two SAGE instruments have provided ozone profile data from February 1979 to November 1981 (SAGE I) and from
October 1984 to the present (SAGE II). Because the data coverage of SAGE I is rather limited in space and time, only the SAGE II data are used here. The SAGE II data on CD-ROM cover the period from October 1984 to December 1989 and the altitude range from cloud top to $60.5 \mathrm{~km}$ at $1-\mathrm{km}$ intervals. The validation study of SAGE II ozone measurements by Cunnold et al. [1989] concluded that the SAGE II profiles agree with ozonesonde measurements within $5 \%$ between 16 and $24 \mathrm{~km}$. In this study we show results based on data for above $16.5 \mathrm{~km}$, which is around the altitude of the tropopause in the equatorial region. Incorporating the pressure and temperature data included in the GEDEX CDROM, we calculate ozone column density $\varepsilon$ (amount of column ozone per kilometer of altitude) from the ozone mixing ratio data. The total ozone amount from the SAGE observation is then defined by summing up the column density from 16.5 to $60.5 \mathrm{~km}$; this sum is taken as the total column amount above $16 \mathrm{~km}$. Hereinafter, this value is referred to as SAGE total ozone.

Soundings are made regularly at an interval of about $24^{\circ}$ longitude with a gradual shift in latitude. Because sampling latitudes are usually different each day between sunrise and sunset, we create a combined data set from the sunrise and sunset data to reduce sampling noise. The averaging of the sunrise and sunset data has been done after processing the two data sets separately following the procedure described below. By using 15 sequential observations covering one entire latitude circle, we calculate a zonal mean and Fourier coefficients of zonal wave components with a $1^{\circ}$ latitude interval. After careful examination of the coherence and stationarity of signals in time and space, we come to the conclusion that in addition to the zonal mean values, wave 1 and 2 components are significant in the equatorial lower stratosphere; smaller-scale structures having wavenumbers 3 and above are considered sporadic and nonstationary. Since there are about eight observations a year at some latitude for each sunrise and sunset, we interpolate the zonal mean and coefficient data on the center of each month for each latitude from $40^{\circ} \mathrm{S}$ to $40^{\circ} \mathrm{N}$. Then the data are averaged over a $5^{\circ}$ latitude band to define values at each $2.5^{\circ}$ latitude interval. Finally, the sunrise and sunset data are averaged. For comparison, we also use the monthly mean TOMS total ozone data, which are identical to the data used by $\mathbf{S 9 2}$.

\section{Annual Cycle}

Figure 1a shows a time-longitude section of the SAGE total ozone field over the equator; time series of the zonal mean values are plotted as a solid curve for the SAGE total ozone and as a dashed curve for the TOMS total ozone (Figure $1 \mathrm{~b}$ ). To pay attention to long-term variations, we have applied a 5-month running mean to most figures showing the 5-year data span, with the exception that a 9-month running mean is applied to Figures 12 and 13; no filtering is used for figures showing the climatological field. In regard to zonal mean values (Figure 1b), temporal variation of the SAGE total ozone is in good accord with that of the TOMS total ozone, with an offset of about -25 Dobson units (DU). This offset value is consistent with the tropospheric column amount of ozone $(\approx 20 \mathrm{DU})$ calculated from a representative value of the tropospheric mixing ratio $(\approx 0.03 \mathrm{ppm})$. Thus most of the residual, i.e., the TOMS minus the SAGE total ozone, could be attributable to tropospheric ozone. How- 
ever, the longitudinal structure is quite different in the TOMS and SAGE observations. In the SAGE total ozone field, the wave 1 structure observed in the TOMS field is not clear, while the wave 2 structure is relatively dominant.

In order to focus on the annual cycle, we present a climatological time series by averaging over 5 years of the SAGE data for each month (Figure 2). The TOMS climatology plotted in Figure $2 b$ (with a shift of $-20 \mathrm{DU}$ ) is defined by averaging monthly mean values during the same period as the SAGE. The zonal mean values of the SAGE total ozone follow a seasonal evolution similar to that of the TOMS, with about -25-DU offset. A semiannual harmonic amplitude for the SAGE (2.3 DU) is smaller than that for the TOMS (3.5 DU). This difference might be due to the sparser data density of the SAGE observation in time, particularly during May and June [see McCormick et al., 1989, Figure 1]. Compared with Figure 2 a of $S 92$, it is surprising that the wave 1 structure, which is conspicuous in the TOMS total ozone field, is almost missing in the SAGE field but that there exists a stationary wave 2 structure. If the residual (TOMS minus SAGE total ozone) does represent the tropospheric ozone amount as originally proposed by Fishman and Larsen [1987], the wave 1 structure should be interpreted as a persistent feature of the tropospheric ozone in the tropics.

In $\mathbf{S 9 2}$ it was hypothesized that the strong upward motion or the higher tropopause associated with the vigorous convective cloud activity in the western Pacific could bring about relatively less ozone in the lower stratosphere, resulting in the wave 1 structure seen in the TOMS total ozone field. This view was supported by a similar structure in the lower stratospheric temperature (S92). However, the lack of a significant wave 1 pattern in the SAGE total ozone (Figure
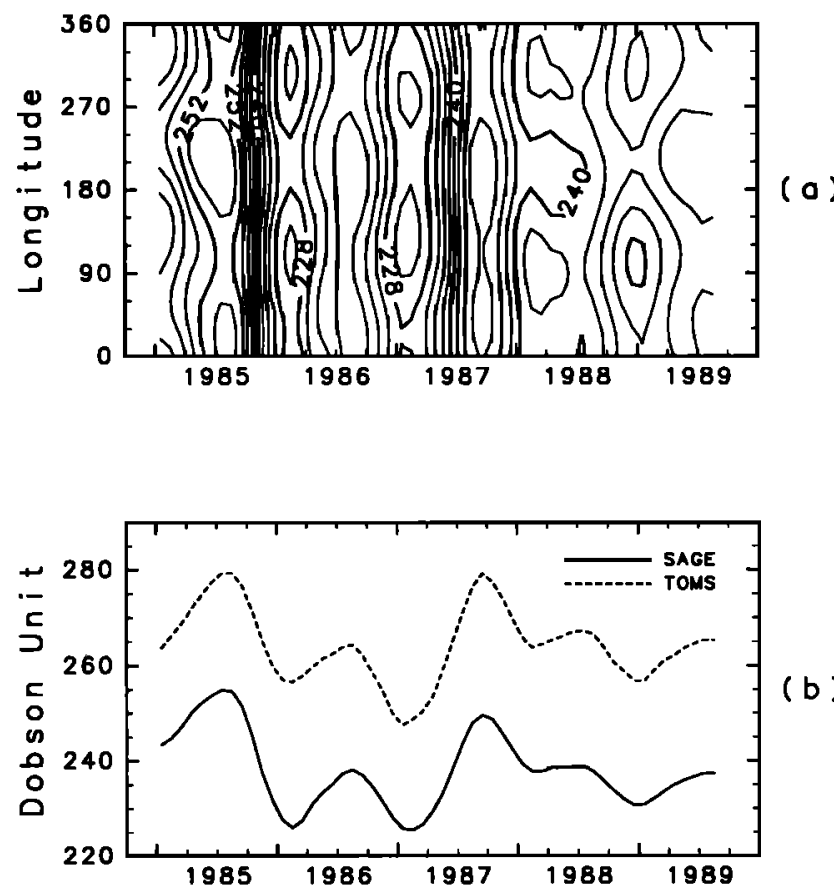

(b)

Figure 1. (a) Time-longitude section of the Stratospheric Aerosol and Gas Experiment (SAGE) total ozone field over the equator (contour interval, 3 Dobson units (DU)) and (b) curve plots of the SAGE zonal mean values (solid curve) and the total ozone mapping spectrometer (TOMS) zonal mean values (dashed curve).

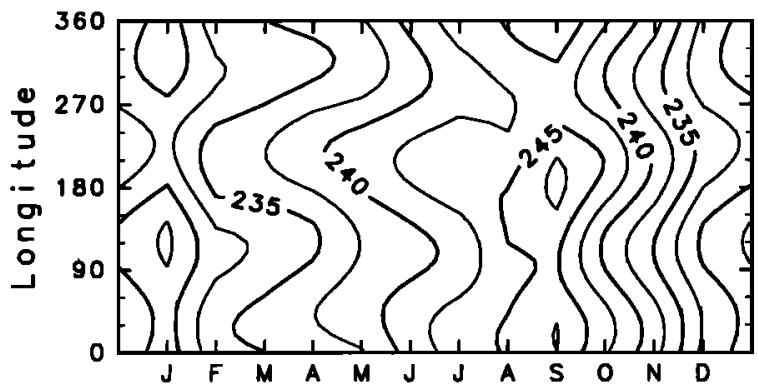

(a)

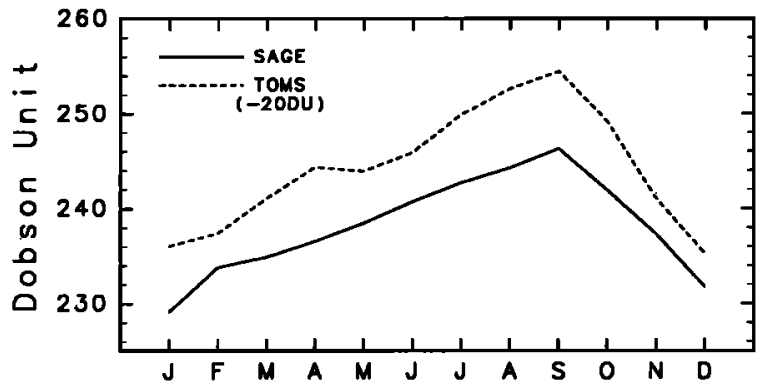

(b)

Figure 2. Climatological annual cycle of the SAGE total ozone field over the equator: (a) time-longitude section (contour interval, $2.5 \mathrm{DU}$ ); (b) curve plots of the SAGE zonal mean values (solid curve) and the TOMS zonal mean value (dashed curve; $-20-D U$ offset).

2a) contradicts this hypothesis. Instead, Fishman et al. [1990] argued that the enhancement of the residual (TOMS minus SAGE total ozone) in the eastern Atlantic from July to October is due to the large concentration of tropospheric ozone photochemically produced by widespread biomass burning during the Brazilian and African dry seasons. Their results have been supported by ozonesonde observations at Natal, Brazil ( $\left.6^{\circ} \mathrm{S}, 35^{\circ} \mathrm{W}\right)$ [Logan and Kirchhoff, 1986], and Brazzaville, Congo $\left(4^{\circ} \mathrm{S}, 15^{\circ} \mathrm{E}\right)$ [Cros et al., 1992]. On the other hand, by using a global spectral model along with the observed flow field, Krishnamurti et al. [1993] have recently pointed out that three-dimensional advection can produce a maximum of tropospheric ozone over the south Atlantic during October even if chemical ozone production is ignored. These observations and model results call attention to the longitudinal inhomogeneity in the tropospheric ozone.

Making use of the SAGE profile data, we can identify where the main contribution to the wave 2 structure in the SAGE total ozone field comes from. Because our supplementary analysis showed that deviations from the zonal mean value in ozone are almost stationary throughout the year and throughout the stratosphere, we present the annual mean deviation field of column density over the equator as a longitude-height section in Figure 3. Vertical integration of this field represents the longitudinal asymmetry of the SAGE total ozone field. It is clear that the wave 2 structure of column density is located just above the tropopause level, while less prominent wave 1 structure is found in the middle stratosphere.

Perliski and London [1989], using 9 years of solar backscattered ultraviolet (SBUV) ozone profile data, showed that there are two maxima in the wave 1 amplitude over the 


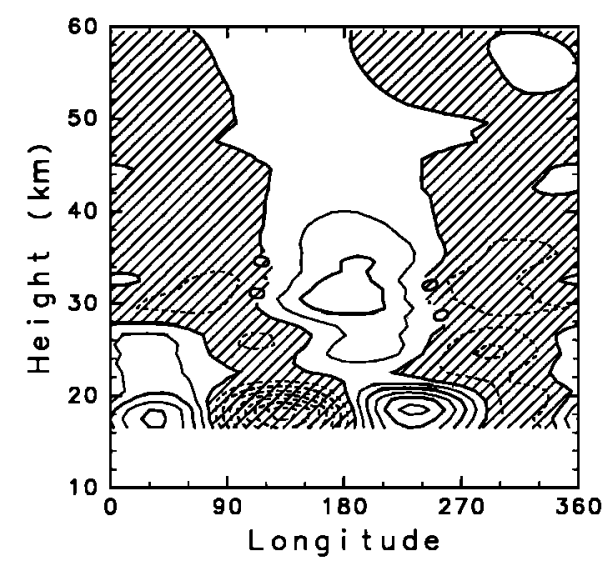

Figure 3. Longitude-height section of the annual mean deviation field (zonal mean values are subtracted) of column density over the equator (contour interval, 0.05 $\mathrm{DU} \mathrm{km}^{-1}$ ).

tropics during all seasons, one at $10 \mathrm{hPa}$ and the other at $\mathbf{4 0}$ $\mathrm{hPa}$. As shown in Figure 3, however, there is no wave 1 maximum around $40 \mathrm{hPa}$ (about $22 \mathrm{~km}$ ) in our SAGE analysis. The discrepancy could be attributable to indirect measurement by the SBUV instrument of the ozone amount below $10 \mathrm{hPa}$. Namely, in the archival SBUV ozone profiles, the ozone amount in the lower stratosphere is deduced from the observed total ozone, the column amount above $10 \mathrm{hPa}$, and regression relationships based on the climatological ozone distribution observed by a balloon-borne instrument. Because the climatological tropospheric profile is set constant along latitude circles, we would get wave 1 structure not in the troposphere but in the lower stratosphere. Thus the lower maximum of the wave 1 structure shown by Perliski and London [1989] should be an artifact, although the weak wave 1 component of the SAGE field in the middle stratosphere may correspond to their upper maximum.

The wave 2 structure at the bottom of the stratosphere seems to be related to zonally asymmetric atmospheric circulations in the equatorial troposphere which are associated with SST variations in longitude. These circulations are usually recognized as east-west overturnings with upward motion over equatorial Africa, Central and South America, and the Maritime Continent. The most dominant cell in the equatorial Pacific is referred to as the Walker circulation. These circulations are modified through changes in the active region of convective clouds in relation with the ENSO events. Although the hypothesis presented in S92, that is, that a higher tropopause with a stronger upward motion would result in less ozone in the lower stratosphere, could be inappropriate to explain the wave 1 structure in the TOMS total ozone field, it is still valid in explaining the wave 2 structure. That is, smaller values of ozone appear over the western Pacific and South America, corresponding to upward branches of the zonally asymmetric circulations along the equator. We cannot resolve the expected low values over Africa, owing to the limitation of using up to wave 2 components. However, the agreement between low values in ozone and upward motion of the zonally asymmetric circulations is fairly good for most locations.

Another interesting feature of the annual variation in zonal mean total ozone shown in $\mathbf{S 9 2}$ is an oscillation of minimum values between $15^{\circ} \mathrm{N}$ and $10^{\circ} \mathrm{S}$ of the winter hemisphere.
This feature is clearly seen also in the SAGE climatology (Figure 4), though the latitudinal range of the oscillation is wider in the SAGE field than in the TOMS field. The oscillation is wider because the latitudinal gradient of the zonal mean values from the equator to the extratropics is smaller in the SAGE than in the TOMS total ozone field. This is because the residual (TOMS minus SAGE total ozone), representing the column amount of ozone below 16 $\mathrm{km}$, should be smaller, as a reflection of the higher tropopause, at equatorial latitudes than at mid and high latitudes.

To investigate the oscillation of minimum values around the equatorial latitude, we make a harmonic analysis to calculate the annual amplitude and phase of the zonal mean ozone amount at each latitude-height grid point. Our results viewed in the mixing ratio (not shown) are essentially similar to those obtained by Perliski and London [1989] using the 9 year's of SBUV data. Since our main concern is an interpretation of the annual variation in total ozone, annual harmonic amplitudes and phases of column density are plotted in Figure 5. At extratropical latitude for both hemispheres, the largest amplitude appears in the lower stratosphere and the next largest one appears in the middle stratosphere. The maxima of the annual cycle occur during the summer in the middle stratosphere and during the early spring in the lower stratosphere. Perliski et al. [1989] showed that the annual ozone variation in the middle stratosphere is controlled largely by the annual variation in the odd-oxygen production rate associated with a change in the solar zenith angle, while dynamically forced variations related to large-amplitude planetary waves during winter and spring are important in the lower stratosphere. From Figure 5a it is easy to recognize that the annual cycle in total ozone at extratropical latitudes is determined mainly from the contribution in the lower stratosphere, though slight cancellation occurs from the oppositely phased middle stratospheric variations. Around the equator, however, the structure is rather complicated, so that a careful examination is necessary for understanding the annual cycle in ozone.

The annual variation in the lower stratospheric ozone is further investigated by dividing it into two modes, the symmetric mode and the asymmetric mode, with respect to the equator. The symmetric mode is defined as $(\varepsilon(y)+$ $\varepsilon(-y)) / 2$, and the asymmetric mode is defined as $(\varepsilon(y)-$ $\varepsilon(-y)) / 2(y$ is latitude). Figure 6 shows the annual amplitude and phase of the column density for these two modes.

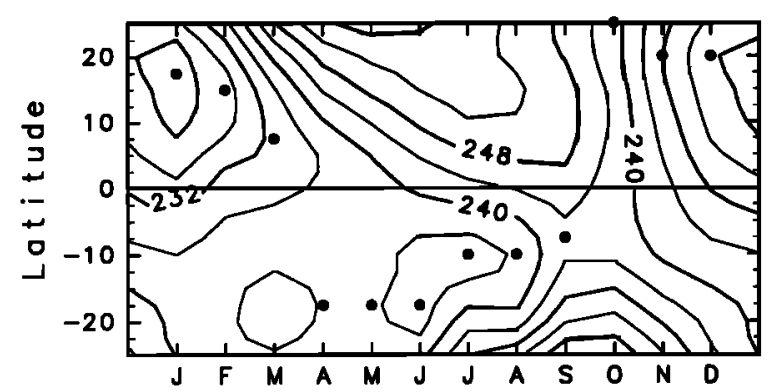

Figure 4. Climatological time-latitude section of the zonal mean SAGE total ozone around equatorial latitudes $\left(25^{\circ} \mathrm{S}-\right.$ $25^{\circ} \mathrm{N}$; contour interval, $\left.4 \mathrm{DU}\right)$. Latitudinal minima are plotted for each month. 

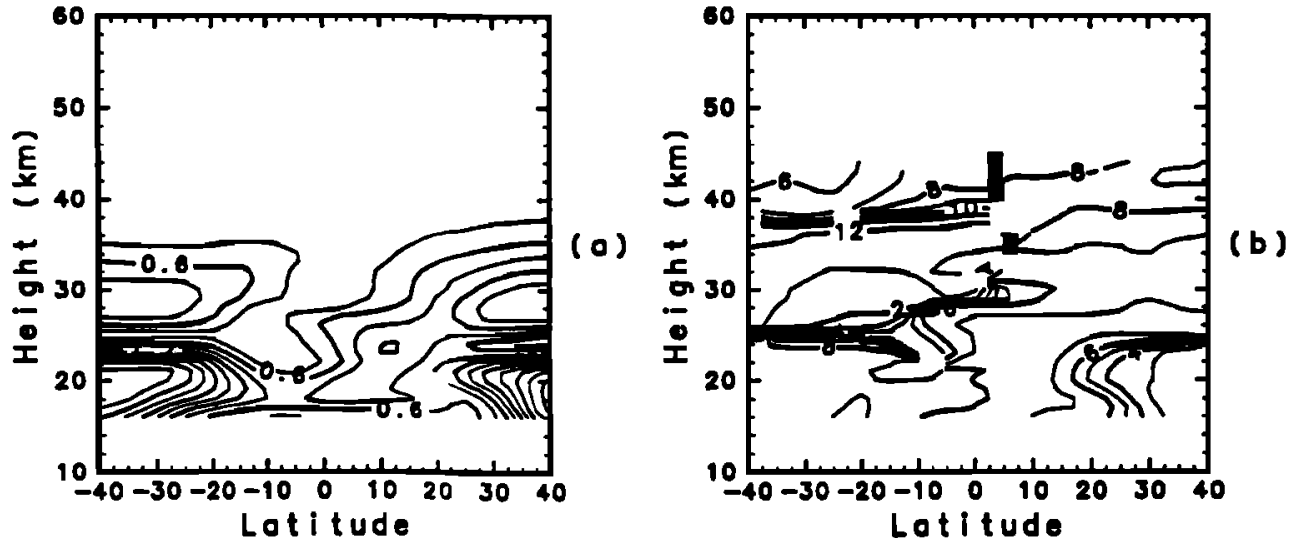

Figure 5. Latitude-height sections of (a) the amplitude (contour interval, $0.3 \mathrm{DU} \mathrm{km}^{-1}$ ) and (b) the phase (units are months) for the annual variation in zonal mean column density.

The maximum annual amplitudes of the symmetric mode (Figure 6a) lie within a thin layer around the bottom of the stratosphere $(18-20 \mathrm{~km})$, with the phase of maxima in August. Examples of the latitudinal structure are illustrated in the time-latitude sections of the climatological zonal mean column density (Figure 7). Just above the tropopause level (Figure $7 \mathrm{a}$ at $18.5 \mathrm{~km}$ ), the annual variation around the equatorial latitude is almost symmetric with respect to the equator, though minimum values usually appear in the southern hemisphere between the equator and $10^{\circ} \mathrm{S}$. Further discussion about the symmetric variation around the bottom of the equatorial stratosphere will be given later.

The asymmetric mode (Figure 6c) has two extratropical maxima similar to those of Figure 5a. As described above,
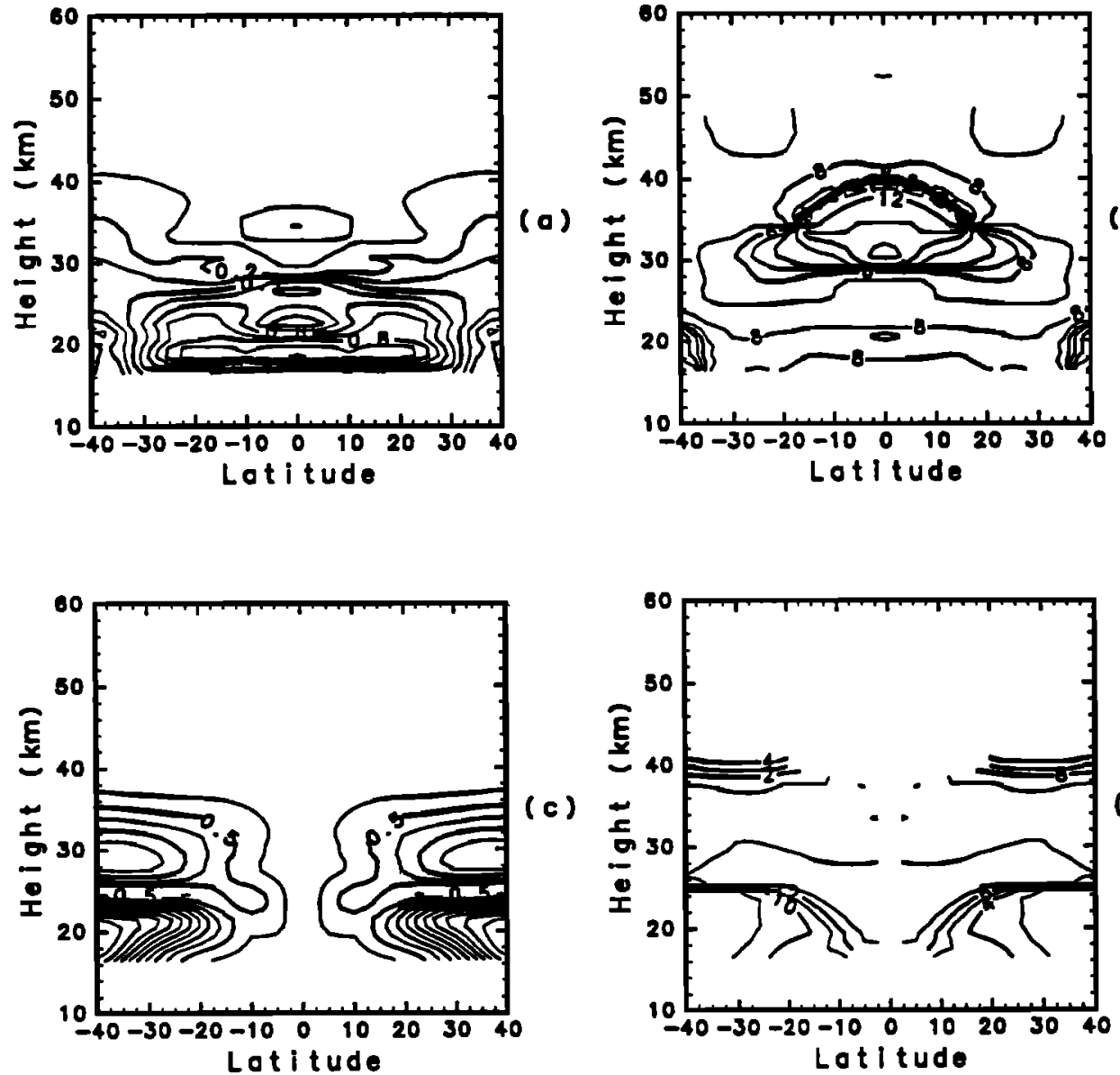

(d)

Figure 6. Latitude-height sections of (a) the amplitude (contour interval, $0.1 \mathrm{DU} \mathrm{km}^{-1}$ ) and (b) the phase (units are months) for the symmetric mode of the annual variation in zonal mean column density and for (c) the annual amplitude (contour interval, $0.25 \mathrm{DU} \mathrm{km}^{-1}$ ) and (d) the phase (units are months) for the asymmetric mode. 


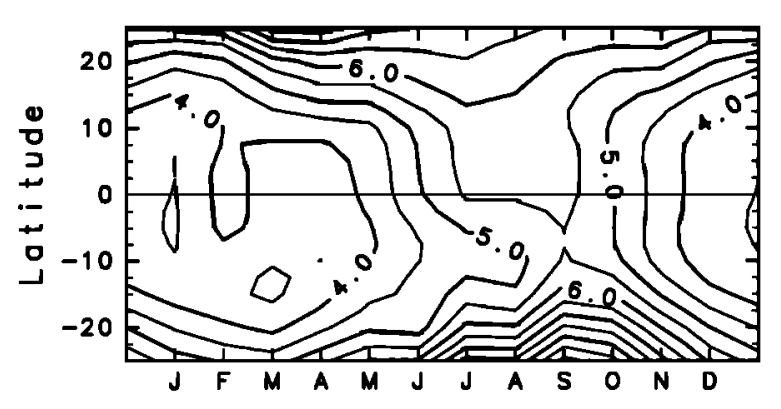

(a)

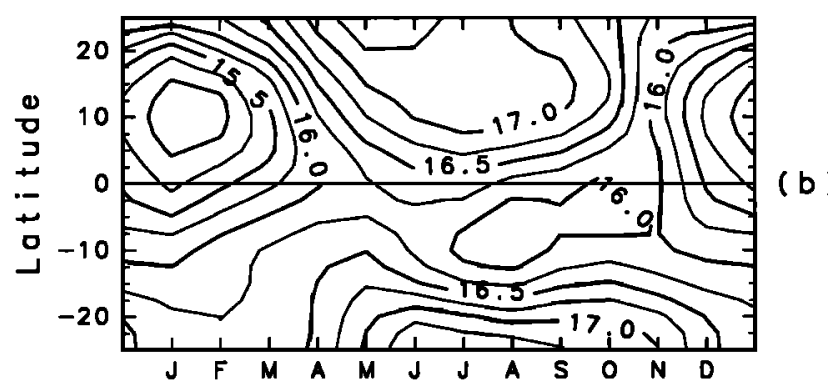

Figure 7. Climatological time-latitude sections of zonal mean column density around equatorial latitudes $\left(25^{\circ} \mathrm{S}-\right.$ $25^{\circ} \mathrm{N}$ ) at (a) $18.5 \mathrm{~km}$ (contour interval, $0.5 \mathrm{DU} \mathrm{km}^{-1}$ ) and (b) $24.5 \mathrm{~km}$ (contour interval, $0.25 \mathrm{DU} \mathrm{km}^{-1}$ ).

the upper maximum is due to the photochemical origin and the lower one is due to the dynamical origin. Around the equatorial latitude, it is interesting to observe that the upper maximum projects into the equatorial latitude around $24 \mathrm{~km}$ (Figure 6c) and that a nodal line of the phase change between the two maxima in the middle and lower stratosphere goes down to the tropopause level (Figure 6d). An example of the time-latitude section at $24.5 \mathrm{~km}$ (Figure $7 \mathrm{~b}$ ) clearly shows this asymmetry. These results suggest that the photochemical effect is still important down in the lower stratosphere (around $25 \mathrm{~km}$ ) at equatorial latitudes; this is consistent with the idea that the solar UV could penetrate deeper and that dynamical transport is relatively weaker around the equator. In fact, by using a simple photochemical model and off-line transport calculation, K. Yamazaki and M. Chiba (private communication, 1993) have recently demonstrated that the asymmetric mode of the annual ozone variation in the equatorial lower stratosphere is due to the photochemical effect associated with a change in the solar zenith angle. Thus even around the equatorial latitude we can still see the asymmetric annual variation resulting from the photochemical effect, though the amplitudes are relatively small compared with those at mid- and high latitudes. The annual variation of the total ozone with a latitudinal oscillation of minimum values (Figure 4 ) is a result of the superposition of these two modes.

It is interesting to see other meteorological parameters showing clear annual variations in the equatorial lower stratosphere (or around the tropopause level). Temperatures in the lower stratosphere show an annual cycle with an amplitude of about $4 \mathrm{~K}$ and a phase with maxima in August [Newell et al., 1969; Reed and Vlcek, 1969; Yulaeva et al., 1994]. In relation to the temperature variation in the lower stratosphere, the tropical Pacific tropopause is about $1-2 \mathrm{~km}$ higher and $5 \mathrm{~K}$ colder during the northern hemisphere winter than during the northern hemisphere summer [Reid and Gage, 1981]. These annual variations have been understood as a result of an annual modulation of the equatorial upward motion, which may be viewed as the ascending branch of the global meridional circulation. The modulation of the upward motion has recently been attributed to the asymmetric variability of the planetary-scale wave forcing between the northern and southern hemispheres as described below.

Holton [1990] and Rosenlof and Holton [1993] estimated the upward mass flux from the troposphere to the stratosphere in the tropics on the basis of a concept of "downward control" proposed by Haynes and McIntyre [1987] and Haynes et al. [1991]. They found that the upward mass flux in the tropics is maximum during the northern hemisphere winter and minimum during the southern hemisphere winter as a result of the stronger planetary-scale eddy forcing at mid and high latitudes in the northern hemisphere winter than in the southern hemisphere winter. Recently, on the basis of calculations from a general circulation model, Iwasaki [1992] has shown similar features on the annual variations of the upward motion and the temperature in the equatorial lower stratosphere.

As suggested by $\mathrm{H} 93$, the stronger upwelling which penetrates the lower stratosphere brings about lower temperatures there through adiabatic cooling. Then the tropopause height would be higher, resulting in less total ozone owing to a deeper layer with low tropospheric ozone concentration. In fact, if we accept the observational evidence of an annual variation in tropopause height as reported by Reid and Gage [1981], the annual variation in total ozone could be reproduced from the tropopause height changes (H93). However, we have no satisfactory explanation for the physical mechanism of the tropopause height changes yet. The annual cycle of the tropopause height must be coupled with the vertical atmospheric motion so that a separate treatment of the two effects, the tropopause effect and the advection effect introduced by $\mathrm{H} 93$ in the interpretation of the QBO and ENSO timescale variations, is no longer effective in understanding the annual cycles.

\section{QBO and ENSO Cycles}

In order to investigate variations with a period longer than 1 year, an anomaly field is constructed by subtracting the climatological annual cycle from the original data. A similar procedure performed in S92 depicted the QBO- and ENSOrelated variations in total ozone. In a time-height section of the zonal mean anomaly field in column density over the equator (Figure 8), these two variations are clearly captured at different height ranges. At a glance, there are three regions of maximum variations around 19,24 , and $32 \mathrm{~km}$. The latitudinal structures of the lower two variations are shown in the time-latitude sections of the anomaly field of the zonal mean column density at 18.5 and $24.5 \mathrm{~km}$ (Figure 9). They have maximum amplitudes almost over the equator. The variations centered near 24 and $32 \mathrm{~km}$ with a periodicity of about 2-3 years are definitely related to the equatorial zonal wind QBO (e.g., see Figure 6 of $\mathrm{S} 92$ as a reference of the equatorial zonal wind). On the other hand, the overall structure around 16-20 km with a time scale of about 3 to 4 years seems to be associated with the ENSO cycle, although 


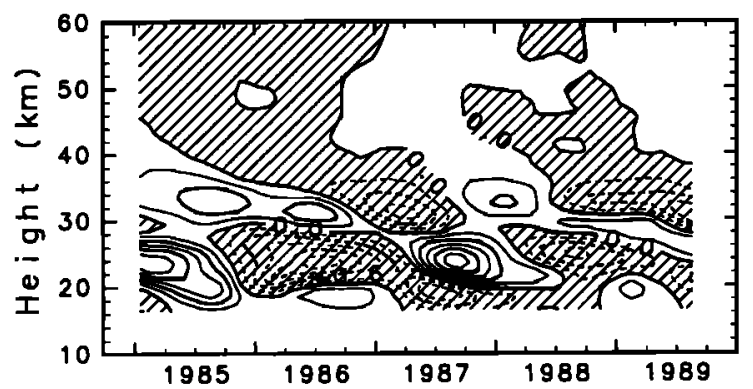

Figure 8. Time-height section of the anomaly field of zonal mean column density over the equator (contour interval, 0.3 DU $\left.\mathrm{km}^{-1}\right)$. Negative values are hatched.

the data length available here extends only 5 years and there are contributions from higher frequencies. Following S92, we investigate the QBO- and ENSO-related variations including the longitudinal structure; we will present the SAGE total ozone field first for each variation to confirm consistency with the TOMS results in S92.

The longitudinal structure of the anomaly field in the SAGE total ozone is shown in Figure 10. There appears to be a clear QBO signal with zonally uniform phase changes in the SAGE total ozone field; this is almost identical to Figure 5 of S92. The zonally uniform phase structure can be seen at almost all levels where the ozone QBO is dominant; Figure 11 shows an example at $24.5 \mathrm{~km}$. The phase discontinuity around the $30-\mathrm{km}$ level (see Figure 8 ) is due to the change in the relative importance of the dynamical effect and photochemical effect [Ling and London, 1986]. The ozone QBO below this level has been understood to be a result of the

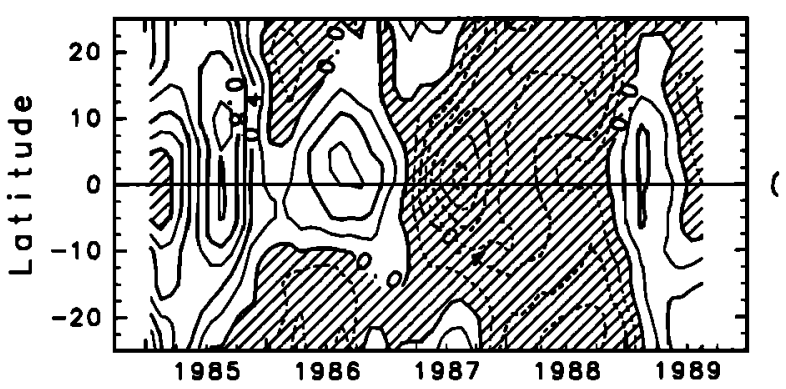

(a)

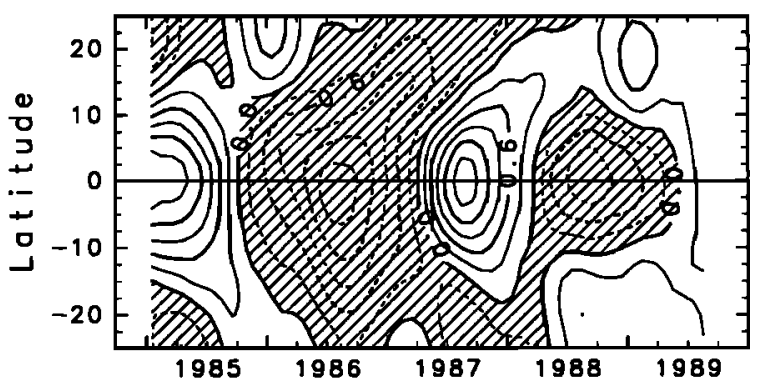

(b)

Figure 9. Time-latitude sections of the anomaly field of zonal mean column density around equatorial latitudes $\left(25^{\circ} \mathrm{S}-25^{\circ} \mathrm{N}\right.$ ) at (a) $18.5 \mathrm{~km}$ (contour interval, $0.2 \mathrm{DU} \mathrm{km}^{-1}$ ) and (b) $24.5 \mathrm{~km}$ (contour interval, 0.3 DU km${ }^{-1}$ ). Negative values are hatched.

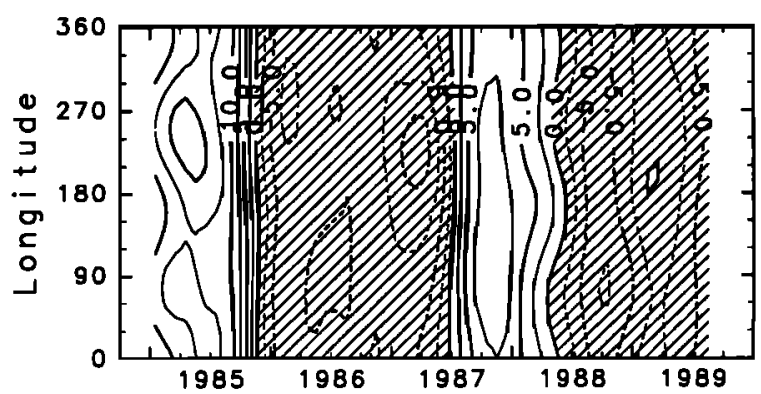

Figure 10. Time-longitude section of the anomaly field of the SAGE total ozone over the equator (contour interval, 2.5 DU). Negative values are hatched.

vertical ozone advection which is driven to maintain the temperature structure against radiative damping [cf. Plumb and Bell, 1982; Andrews et al., 1987]. However, Hasebe [1994] has recently pointed out that it is important to include the feedback of the ozone QBO to the diabatic heating through the absorption of solar radiation.

We next subtract zonal mean values from Figure 10 to investigate the zonal wave component in the SAGE total ozone anomaly field (Figure 12). There appears to be an east-west variation with a nodal longitude around the date line, which is basically similar to that reported in S92; the similarity between the two results from different observations enhances confidence in its reality. As pointed out in S92, this variation seems to be closely related to the ENSO cycle. Within the 5 years of this analysis, one El Niño event (a so-called "warm event") occurred around the end of 1986 to the beginning of 1987 and was followed by a La Niña ("cold event") in 1988-1989. During the El Niño event the longitudinal deviation field in total ozone is positive in the eastern hemisphere and negative in the western hemisphere; the anomaly pattern is reversed during the La Niña event.

The ENSO-related variation of ozone can be seen in the SAGE profile data. Figure 13 shows time-longitude sections of column density at $18.5 \mathrm{~km}$ over the equator with zonal mean values retained (Figure 13a) and subtracted (Figure 13b). From Figure 13a, showing zonally uniform phase changes of the variation, it is clear that zonal mean values around the bottom of the stratosphere vary with a timescale of about 3-4 years as shown in Figures 8 and 9a. The longitudinal deviation field at $18.5 \mathrm{~km}$ (Figure 13b) also shows a clear east-west vacillation associated with the ENSO cycle. This east-west pattern is essentially similar to

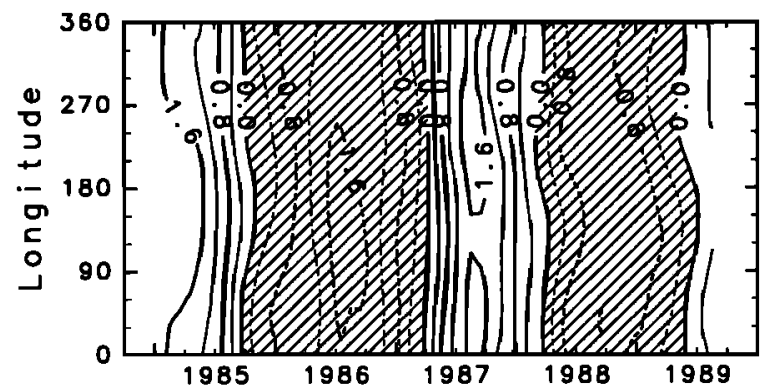

Figure 11. Time-longitude section of the anomaly field of column density over the equator at $24.5 \mathrm{~km}$ (contour interval, $0.4 \mathrm{DU} \mathrm{km}^{-1}$ ). Negative values are hatched. 


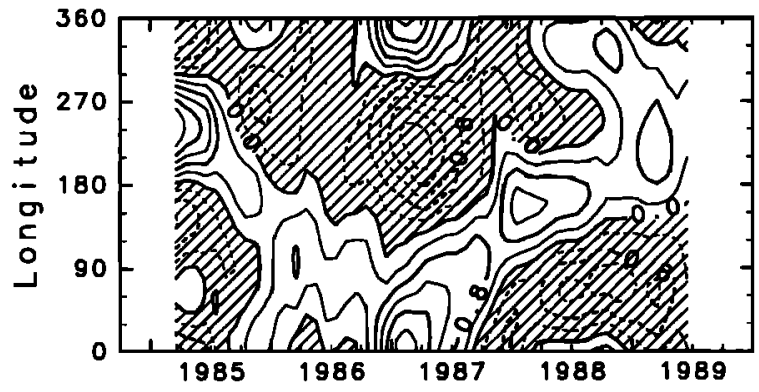

Figure 12. Time-longitude section of the anomaly field of the SAGE total ozone over the equator (zonal mean values are subtracted; contour interval, $0.4 \mathrm{DU})$. Negative values are hatched.

that in Figure 12; there were positive anomalies in the eastern hemisphere and negative anomalies in the western hemisphere when the El Niño event occurred.

These results are consistent with an interpretation of the ENSO timescale ozone variation proposed by H93. Because the SSTs in the eastern Pacific are higher during the El Niño event than during the La Niña event, an active region of convective clouds moves relatively eastward. Associated with this movement of convective cloud activity, the tropopause height would be relatively higher in the eastern Pacific during the El Niño event. Gage and Reid [1987] showed that the tropopause height change is correlated with the ENSO cycle in this way, though their analysis is confined mainly to the western Pacific. According to H93, the tropopause effect associated with the change in the east-west tropopause height variation would bring about the east-west vacillation of ozone as seen in Figures 12 and 13b. The advection effect accompanied by increased upward motion extending along the equator would cause the decreasing tendency of ozone as shown in Figures 8, 9a, and 13a. Namely, during the mature stage of the El Niño event, the east-west contrast and the decreasing zonal mean tendency are at a maximum; note the phase difference between the two effects in Figures 13a and 13b. In H93's calculation, the vertical extent of the two effects, the tropopause effect and the advection effect, is assumed to be limited only up to just above the tropopause level $(17 \mathrm{~km})$. Although there was no reasonable explanation for selecting this upper bound in $\mathrm{H} 93$, it is consistent with the present results in the sense that the ENSO-related variation is restricted to the thin height range at the bottom of the stratosphere.

Reid and Gage [1985] and H93 suggested that there exists a tropopause height modulation due to the zonal wind QBO. When the cold anomaly associated with the easterly shear of the QBO reaches the bottom of the stratosphere, the buoyant motion of the tropospheric air mass can reach higher altitudes than normal, resulting in greater elevation of the tropopause. During the period of our analysis, the tropopause may have been lifted twice, around the end of 1984 to the beginning of 1985 and in 1987, when the easterlies penetrated the lower stratosphere. Because of the tropopause effect, the variation in ozone would show a negative anomaly then. This is consistent with our results, depicted in Figures 8, 9a, and 13a, although the ENSOrelated variation seems to surpass the $Q B O$ variation around the bottom of the stratosphere.
As was mentioned in our discussion on the QBO, the feedback of the ozone perturbations to diabatic circulation through absorption of solar radiation could be important for the ozone QBO [Hasebe, 1994]. We briefly discuss whether a similar feedback process is important for the ENSOrelated ozone variations. Our examination here is based on the observed perturbations of ozone (Figure 13a) and temperature [Gage and Reid, 1987] together with the use of the radiative parameters published by Ling and London [1986]. That is, an estimation is made for the magnitude of two diabatic heating terms in the thermodynamic equation [see Ling and London, 1986; Hasebe, 1994]. The first term represents the absorption of solar radiation associated with the ozone perturbations, and the other represents the infrared radiative damping as modeled in the form of Newtonian cooling. Although there is a limitation in this simple treatment in which the radiative heating is proportional to local ozone amount but insensitive to the upper level ozone changes, this will give us an insight into the possible role of the feedback processes on the ENSO-related ozone variations. The result at $20 \mathrm{~km}$ shows that the feedback term is almost 1 order of magnitude smaller than the infrared cooling term. Thus the ENSO timescale ozone fluctuations are too small to modulate the atmospheric heat balance appreciably, although they are large enough when observed in total ozone owing to relatively large atmospheric number density at the bottom of the stratosphere.

\section{Summary}

As an extension of the total ozone analysis by Shiotani [1992], we have investigated equatorial ozone variations using the SAGE ozone profile data for 5 years from 1984 to
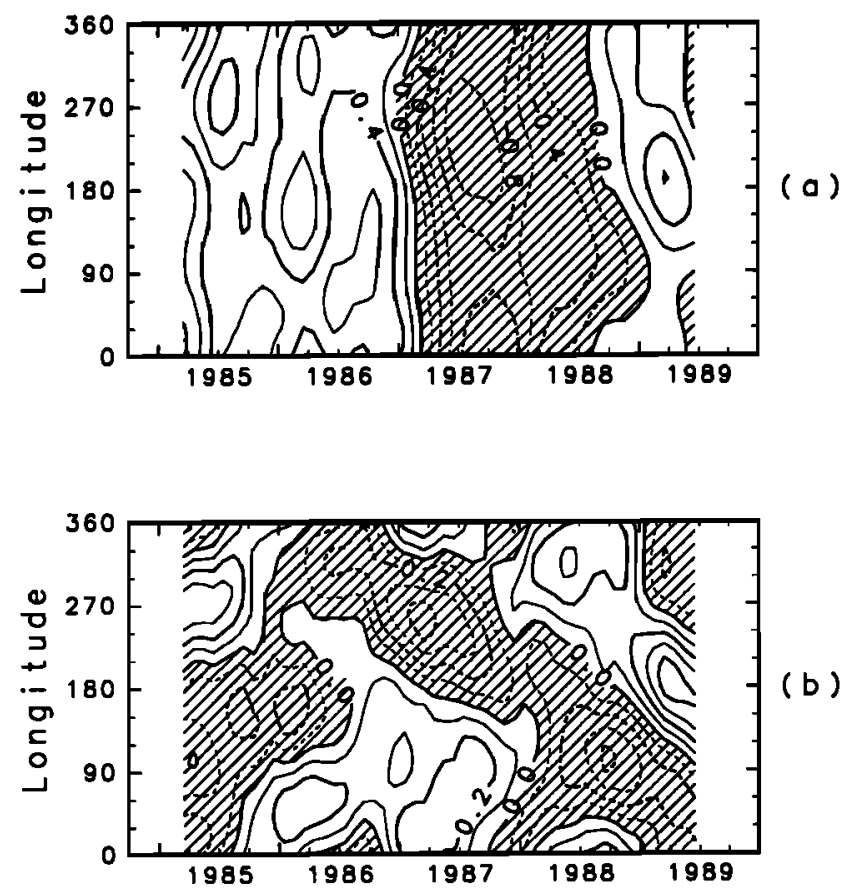

Figure 13. Time-longitude sections of the anomaly field of column density over the equator at $18.5 \mathrm{~km}$ : (a) zonal mean values are included (contour interval, $0.2 \mathrm{DU} \mathrm{km}^{-1}$ ); (b) zonal mean values are subtracted (contour interval, $0.1 \mathrm{DU}$ $\mathrm{km}^{-1}$ ). Negative values are hatched. 
1989. In particular, we have focused our attention on the longitudinal and altitudinal structures of variations with timescales from annual to about 4-year periodicities in the lower stratosphere, where the largest contribution to total column ozone takes place.

Over the equator there exists a prominent annual variation in column ozone density at the bottom of the stratosphere. This variation might be associated with changes in tropopause height resulting from modulation in the global meridional circulation driven by the planetary-scale wave forcing in the extratropical latitude. Because the planetary wave activity is more vigorous in the northern hemisphere winter than in the southern hemisphere winter, the upward motion around the equator, which is regarded as the upward branch of the global meridional circulation, is stronger in the northern hemisphere winter than in the southern hemisphere winter. Consequently, the equatorial lower stratosphere becomes cooler through adiabatic cooling and the tropopause becomes higher. Thus the deeper troposphere with a small tropospheric ozone amount is directly coupled with the annual variation in total ozone. Moreover, the latitudinal oscillation of the tropical minimum values in the zonal mean total ozone is attributable to the asymmetric annual variation in ozone around $25 \mathrm{~km}$. This feature can be interpreted as the photochemical effect associated with the $\mathrm{O}_{2}$ photolysis rate varying with the solar zenith angle. As to the longitudinal structure of the annual variation, the persistent zonal wavenumber 1 pattern observed by the TOMS total ozone over the equator is almost missing in the SAGEderived column ozone amounts integrated in the stratosphere. This result suggests the importance of time-space variability in tropospheric ozone.

When the climatological annual cycle is subtracted, clear signals of the ozone QBO above $20 \mathrm{~km}$ and the ENSOrelated variation below $20 \mathrm{~km}$ appear. The ozone QBO shows zonally uniform phase changes both in the total ozone field and in the column density field. The ENSO-related variation consists of the large-scale east-west vacillation and the zonally uniform phase variation. During the mature stage of the El Niño event, there are positive anomalies in the eastern hemisphere and negative anomalies in the western hemisphere, and the decreasing tendency of the zonal mean values is maximum at the same time. These results are consistent with an interpretation of the ENSO timescale ozone variation proposed by Hasebe [1993]. Associated with the eastward movement of convective cloud activity during the El Niño event, the tropopause would be relatively higher in the eastern Pacific. Thus the change in tropopause height would bring about the east-west vacillation of ozone. The advection effect accompanied by increased upward motion extending along the equator would cause the decreasing tendency of zonal mean ozone.

Acknowledgments. We thank Byron A. Boville, Timothy J. Dunkerton, William J. Randel, George C. Reid, and Thomas M. Heslin for their helpful comments on the manuscript and Masaru Chiba and Koji Yamazaki for stimulating discussions. Graphic outputs were made by use of the GFD-DENNOU Library. M.S. acknowledges the hospitality of John C. Gille and his colleagues during his stay at NCAR. F. H., supported by NASA grant NAS531247, expresses gratitude to Marvin A. Geller for the continuous encouragement he gave at Stony Brook. This work was supported in part by a grant-in-aid for Scientific Research, the Ministry of Education, Science, and Culture of Japan and by the
Sumitomo Foundation. The National Center for Atmospheric Research is sponsored by the National Science Foundation.

\section{References}

Andrews, D. G., J. R. Holton, and C. B. Leovy, Middle Atmosphere Dynamics, 489 pp., Academic, San Diego, Calif., 1987.

Cros, B., D. Nganga, A. Minga, J. Fishman, and V. Brackett, Distribution of tropospheric ozone at Brazzaville, Congo, determined from ozonesonde measurements, J. Geophys. Res., 97, $12,869-12,875,1992$.

Cunnold, D. M., W. P. Chu, R. A. Barnes, M. P. McCormick, and R. E. Veiga, Validation of SAGE II ozone measurements, $J$. Geophys. Res., 94, 8447-8460, 1989.

Fishman, J., and J. C. Larsen, Distribution of total ozone and stratospheric ozone in the tropics: Implications for the distribution of tropospheric ozone, J. Geophys. Res., 92, 6627-6634, 1987.

Fishman, J., C. E. Watson, J. C. Larsen, and J. A. Logan, Distribution of tropospheric ozone determined from satellite data, J. Geophys. Res., 95, 3599-3617, 1990.

Gage, K. S., and G. C. Reid, Longitudinal variations in tropical tropopause in relation to tropical convection and El NiñoSouthern Oscillation events, J. Geophys. Res., 92, 14,197-14,203, 1987.

Hasebe, F., Dynamical response of the tropical total ozone to sea surface temperature changes, J. Atmos. Sci., 50, 345-356, 1993.

Hasebe, F., Quasi-biennial oscillations of ozone and diabatic circulation in the equatorial stratosphere, J. Atmos. Sci., 729-745, 1994.

Haynes, P. H., and M. E. McIntyre, On the evolution of vorticity and potential vorticity in the presence of diabatic heating and frictional or other forces, J. Atmos. Sci., 44, 828-841, 1987.

Haynes, P. H., C. J. Marks, M. E. McIntyre, T. G. Shepherd, and K. P. Shine, On the "downward control" of extratropical diabatic circulations by eddy-induced mean zonal forces, J. Atmos. Sci., $48,651-678,1991$.

Holton, J. R., On the global exchange of mass between the stratosphere and troposphere, J. Atmos. Sci., 47, 392-395, 1990.

Iwasaki, T., General circulation diagnosis in the pressure isentrope hybrid vertical coordinate, J. Meteorol. Soc. Jpn., 70, 673-687, 1992.

Krishnamurti, T. N., H. E. Fuelberg, M. C. Sinha, D. Oosterhof, E. L. Bensman, and V. B. Kumar, The meteorological environment of the tropospheric ozone maximum over the tropical South Atlantic Ocean, J. Geophys. Res., 98, 10,621-10,641, 1993.

Ling, X.-D., and J. London, The quasi-biennial oscillation of ozone in the tropical middle stratosphere: A one-dimensional model, $J$. Atmos. Sci., 43, 3122-3137, 1986.

Logan, J. A., and V. W. J. H. Kirchhoff, Seasonal variations of tropospheric ozone at Natal, Brazil, J. Geophys. Res., 91, 78757881, 1986

McCormick, M. P., P. Hamill, T. J. Pepin, W. P. Chu, T. J. Swissler, and L. R. McMaster, Satellite studies of the stratospheric aerosol, Bull. Am. Meteorol. Soc., 60, 1038-1046, 1979.

McCormick, M. P., J. M. Zawodny, R. E. Veiga, J. C. Larsen, and P. H. Wang, An overview of SAGE I and II ozone measurements, Planet. Space Sci., 37, 1567-1586, 1989.

Newell, R. E., J. W. Kidson, and D. G. Vincent, Annual and biennial modulations in the tropical Hadley cell circulation, $\mathrm{Na}$ ture, 222, 76-78, 1969.

Perliski, L. M., and J. London, Satellite observed long-term averaged seasonal and spatial ozone variations in the stratosphere, Planet. Space Sci., 37, 1509-1525, 1989.

Perliski, L. M., S. Solomon, and J. London, On the interpretation of seasonal variations of stratospheric ozone, Planet. Space Sci., 37 , $1527-1538,1989$.

Plumb, R. A., and R. C. Bell, A model of the quasi-biennial oscillation on an equatorial beta-plane, $Q . J . R$. Meteorol. Soc., $108,335-352,1982$.

Randel, W. J., and J. B. Cobb, Coherent variations of monthly mean total ozone and lower stratospheric temperature, J. Geophys. Res., 99, 5433-5447, 1994.

Reed, R. J., and C. L. Vlcek, The annual temperature variation in the lower tropical stratosphere, J. Atmos. Sci., 26, 163-167, 1969. 
Reid, G. C., and K. S. Gage, On the annual variation in height of the tropical tropopause, J. Atmos. Sci., 38, 1928-1938, 1981.

Reid, G. C., and K. S. Gage, Interannual variations in the height of the tropical tropopause, J. Geophys. Res., 90, 5629-5635, 1985.

Rosenlof, K. H., and J. R. Holton, Estimates of the stratospheric residual circulation using the downward control principle, $J$. Geophys. Res., 98, 10,465-10,479, 1993.

Shiotani, M., Annual, quasi-biennial, and El Niño-Southern Oscillation (ENSO) time-scale variations in equatorial total ozone, $J$. Geophys. Res., 97, 7625-7633, 1992.

Yulaeva, E., J. R. Holton, and J. M. Wallace, On the cause of the annual cycle in the tropical lower stratospheric temperature, $J$. Atmos. Sci., 51, 169-174, 1994.

F. Hasebe, Department of Earth Sciences, Faculty of Science, Ibaraki University, Mito 310, Japan.

M. Shiotani, Department of Geophysics, Kyoto University, Kyoto 606, Japan. (e-mail: Internet shiotani@kugi.kyoto-u.ac.jp)

(Received July 1, 1993; revised December 30, 1993; accepted March 11, 1994.) 